TERRA. Revista de Desarrollo Local e-ISSN: 2386-9968

Número 6 (2020), 204-227

DOI 10.7203/terra.6.17374

IIDL - Instituto Interuniversitario de Desarrollo Local

\title{
Emprendimiento y empleabilidad en el sector turístico en mujeres retornadas desde España y otros países a la Provincia de El Oro (Ciudad de Machala, Ecuador)
}

\author{
Violante Martínez Quintana \\ Profa. Titular de Sociología III. Facultad de Ciencias Políticas y Sociología. UNED \\ (Madrid, España) \\ vmartin@poli.uned.es \\ https://orcid.org/0000-0001-6208-1318 \\ Miguel Ángel Ramón Pineda \\ Universidad Técnica de Machala (Ecuador) \\ mramon@utmachala.edu.ec
}

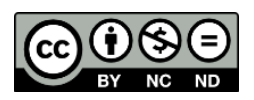

Esta obra se distribuye con la licencia Creative Commons Reconocimiento-NoComercial-SinObraDerivada 4.0 Internacional 


\title{
SECCIÓN ARTÍCULOS
}

\author{
Emprendimiento y empleabilidad en el sector turístico en mujeres retornadas desde España y otros \\ países a la Provincia de El Oro (Ciudad de Machala, Ecuador)
}

Resumen: El emprendimiento y la empleabilidad en el sector turístico de mujeres inmigrantes retornadas es el objeto de estudio de este trabajo, que se vincula con una de las etapas de la migración experimentada por estas mujeres, y las dificultades de integración laboral en el retorno a su país. La hipótesis de partida afirma que el turismo ofrece amplias oportunidades de progreso laboral a las mujeres retornadas. En primer lugar, se analiza el estado en el que se encuentran los cantones turísticos de la Provincia de El Oro (Ecuador), en especial los más vírgenes y poco explotados como los del interior. En segundo lugar, se efectúan dos Focus Groups para conocer a través de las narrativas los obstáculos que enfrentan en su incorporación al sector turístico, los sectores de mayor dificultad y las trayectorias vitales que han atravesado. Se obtiene que, a pesar del importante potencial formativo que poseen, la experiencia laboral consolidada y el poder adquisitivo alcanzado, no es suficiente para obtener una satisfactoria incorporación laboral en uno de los sectores más ricos y productivos como es el turismo, ya que sus oportunidades de progreso laboral quedan mermadas por factores de género, discriminación y desigualdad principalmente.

Palabras clave: progreso laboral, discriminación, turismo interior, turismo tradicional, inmigrantes.

\section{Entrepreneurship and employability in the tourism sector of women returned from Spain and other countries to the Province of El Oro (Ciudad de Machala, Ecuador)}

\begin{abstract}
The entrepreneurship and employability in the tourist sector of returned immigrant women is the object of study of this work, which is linked to one of the stages of migration experienced by these women, and the difficulties of labor integration on the return to their country. The starting hypothesis affirms that tourism offers ample opportunities for job advancement to returned women. Firstly, the state in which the tourist cantons of the Province of El Oro are found, especially the most unspoilt and little exploited such as those in the interior, are analyzed. Secondly, two Focus Groups are held to learn through the narratives of the obstacles they face in their incorporation into the tourism sector, the most difficult sectors and the vital trajectories they have gone through. It is obtained that, despite the important training potential they possess, the consolidated work experience and the purchasing power achieved, it is not enough to obtain a satisfactory job incorporation in one of the richest and most productive sectors such as tourism, since its opportunities of labor progress are diminished by factors of gender, discrimination and inequality mainly.
\end{abstract}

Key words: job progress, discrimination, inland tourism, traditional tourism, immigrants.

Recibido: 11 de mayo de 2020

Devuelto para revisión: 22 de junio de 2020

Aceptado: 10 de julio de 2020

\section{Referencia / Citation:}

Martínez, V., y Ramón, M. A. (2020). Emprendimiento y empleabilidad en el sector turístico en mujeres retornadas desde España y otros países a la Provincia de El Oro (Ciudad de Machala, Ecuador). TERRA. Revista de Desarrollo Local, (6), 204-227. DOI 10.7203/terra.6.17374 
IDEAS CLAVE / HIGHLIGHTS / IDEES CLAU

1. Se investigan las mujeres que han emigrado por cuestiones de sobrevivencia y falta de oportunidades laborales, y que por circunstancias económicas y de crisis se han visto obligadas a retornar a su país de origen.

2. En América Latina el emprendimiento está muy vinculado a estas mujeres ante los problemas económicos y de reinserción laboral que encuentran en su regreso.

3. Destaca su capacidad para adaptar sus capacidades y recursos a las necesidades del mercado laboral, particularmente, del sector turístico.

4. Esta adaptación les favorece el progreso laboral, vía experiencias, conocimientos y habilidades de todo tipo adquiridas en el país de destino.

5. Estas mujeres han de superar un trato diferente, perjudicial y desigual por distintos motivos.
1. Research is carried out on women who have migrated for reasons of survival and lack of work opportunities, and who have been forced to return to their country of origin due to economic circumstances and crises.

2. In Latin America, entrepreneurship is closely linked to these women in the face of the economic and job reinsertion problems they encounter on their return.

3. Stresses its ability to adapt its skills and resources to the needs of the labour market, particularly the tourism sector.

4. This adaptation helps them to progress in their work, through experience, knowledge and skills of all kinds acquired in the destination country.

5. These women have to overcome different, harmful and unequal treatment for various reasons.
1. S'investiguen les dones que han emigrat per qüestions de supervivència i falta d'oportunitats laborals, i que per circumstàncies econòmiques i de crisis s'han vist obligades a retornar al seu país d'origen.

2. A Amèrica Llatina l'emprenedoria està molt vinculat a aquestes dones davant els problemes econòmics i de reinserció laboral que troben en el seu retorn.

3. Destaca la seua capacitat per a adaptar les seues capacitats i recursos a les necessitats del mercat laboral, particularment, del sector turístic.

4. Aquesta adaptació els afavoreix el progrés laboral, via experiències, coneixements i habilitats de tota mena adquirides al país de destinació.

5. Aquestes dones han de superar un tracte diferent, perjudicial i desigual per diferents motius. 


\section{INTRODUCCIÓN}

En los últimos años se ha producido en Ecuador un cambio en el patrón migratorio, con énfasis en el destino y en el sexo de las personas migrantes. Si bien las mujeres han representado siempre una parte significativa en las estadísticas de migración, en las tres últimas décadas se percibe un aumento en la migración femenina por factores económicos asociados a la incertidumbre laboral, la precarización del trabajo, las escasas posibilidades de movilidad social, la pobreza y la falta de empleo. En muchos casos también influyeron las motivos ligados a nuevos proyectos personales, educativos y familiares, así como el deseo de conocer gente y culturas diferentes, y de manera fundamental la búsqueda de desarrollo de oportunidades individuales.

La movilidad humana ha sido "un hecho creciente y un elemento importante de la interdependencia creciente entre los estados, consecuente de la integración económica, la globalización, el desarrollo tecnológico, la política social y cultural que traen consigo circulación de bienes, capitales, servicios, trabajadores y trabajadoras" (Moreno, 2006, p. 121). En América Latina y el Caribe los procesos migratorios han sido constantes, de tal manera que ha ido transformando las sociedades y modificando el comportamiento de los habitantes, que hasta hace algunas décadas se concebían más gregarios, individualistas y ajenos a la convivencia entre personas con diferencias culturales. En esta región se expresan algunas de las manifestaciones migratorias "desde la emigración de latinoamericanos y caribeños, hasta la inmigración, el retorno, la migración irregular, el desplazamiento forzado y la búsqueda de refugio, sumado al flujo de remesas, la migración calificada y la presencia de nutridas comunidades en el exterior" (Martínez, 2011, p. 17).

Este fenómeno se hizo más evidente en la década de los noventa, cuando los flujos migratorios se reorientaron a los países de Europa, destacando España con una alta recepción de mujeres. La mujer que se había mantenido en actividades íntimamente asociadas a las costumbres de una sociedad conservadora, a raíz del éxodo migratorio se vio forzada a modificar sus patrones culturales del cuidado del hogar, la crianza y la educación básica de sus hijos, para emprender en actividades laborales de extenuante esfuerzo en contextos totalmente ajenos a su lugar de origen. Por tanto, la migración ha constituido un tema de gran interés y preocupación, al cumplir la mujer un papel fundamental y prioritario en el núcleo familiar que se fue modificando por la necesidad económica de contribuir al progreso y desarrollo del hogar (Camacho y Hernández, 2005). Entre las repercusiones que han comportado estos movimientos migratorios, sobresale la alteración en los roles de los hijos que quedaban bajo el cuidado y la protección de terceras personas, mientras persistía la ausencia de las madres (López, 2012).

Por su parte, Coronel (2011) sostiene que la migración ha generado una variedad de problemas como el envejecimiento de la población, el decaimiento del rendimiento escolar al disminuir la matrícula, y la disminución de los ingresos públicos como consecuencia de la emigración de la gente trabajadora. Consecuentemente, el tema del retorno ha tomado cierta relevancia en los estudios de la migración internacional, como es el caso de las mujeres retornadas desde España y otros países que han tenido en su regreso dificultades en la inserción laboral dependiendo de los sectores económicos. En el área urbana es donde más se ha concentrado la población empleada en condiciones de subempleo, y en el área rural la población ha tenido un alto porcentaje de participación en el empleo no remunerado (Alarcón y Ordóñez, 2015). 


\section{MARCO TEÓRICO DE REFERENCIA}

El emprendimiento es un término asociado al empoderamiento, y está siendo muy utilizado en todas las latitudes en la actualidad. Según la Escuela Politécnica del Litoral del Ecuador (ESPOL) (2015) el seguimiento global de emprendimiento en América Latina y el Caribe, muestra que las actividades emprendedoras y, la figura del emprendedor han cobrado relevancia debido, entre otros, a iniciativas destinadas a la promoción y ayuda a las actividades de creación de nuevas empresas, aunque muy pocas de ellas se orientan al turismo. En las últimas décadas la actitud de emprender constituye una alternativa ante los problemas económicos de países que sufrieron fuertes oleadas migratorias, y que se agrava cuando los países receptores de migrantes entran en crisis. En consecuencia, se produce el retorno de las personas que abandonaron su país de origen, como es el caso de las mujeres migrantes, que se enfrentan a la reinserción laboral. Se advierte en la literatura especializada que en la medida que se estimule el emprendimiento, la economía familiar de las migrantes retornadas mejorará, ya que desde siempre las mujeres han estado presentes en el desarrollo económico de los pueblos, siendo claves en los procesos de construcción (Pazmiño y Guayasamín, 2017).

Vega (2016) efectúa una aproximación a la literatura del retorno y advierte diferencias en las motivaciones y estrategias en mujeres y hombres. Las mujeres suelen ser reacias al retorno, en gran parte, por el temor a perder el poder adquirido y ante la vuelta a los roles tradicionales, en tanto que para los varones la llegada supone prestigio al menos en los primeros momentos. Se constata toda una extensa discusión sobre la redefinición de las identidades y las relaciones de género que se va a articular en la incorporación a la vida económica, familiar y afectiva, así como una diferencia entre quienes emprenden por oportunidad y quienes lo hacen por subsistencia. Las personas que emprenden por oportunidad ya tenían negocios antes de migrar, y desarrollaron una estrategia de inversión tanto en el país de origen como en el de acogida, optimizando recursos, titulaciones, actores y oportunidades. Las personas que emprenden por subsistencia (normalmente familias monoparentales) tienen situaciones más vulnerables, sobre todo si su plan no era el de retornar.

En el área turística el emprendimiento constituye una alternativa para la reinserción laboral de las mujeres retornadas, a su vez que se convierte en un espacio dignificante y valorativo de la autoestima que había padecido importantes mermas por el abandono forzado del país, de la familia y del entorno connatural; de hecho, las políticas en Ecuador están dedicando gran atención a este tema (Vega, 2016). Asimismo, Oyarvide et al. (2016) expresa que las ideas emprendedoras son procesos que relacionan al individuo emprendedor con las instituciones y el Estado, y esto lleva a convertir el emprendimiento en un fenómeno social y económico muy complejo. Emprender un negocio ofrece mayores oportunidades de ingreso al Estado y a la persona, si bien la percepción de autoeficacia es más baja en las mujeres que en los hombres, y es un factor que va a condicionar, en parte, la decisión de emprender (Carranza et al., 2018).

En el emprendimiento turístico de las mujeres retornadas influye positivamente que el turismo sea una de las principales actividades económicas tanto en países desarrollados como en países en desarrollo (Huízar et al., 2016), pero las asimetrías entre hombres y mujeres han aumentado la desigualdad histórica. Las yuxtaposiciones sociales de las mujeres frente a los hombres deben mejorarse, de manera que se incorporen prácticas e intereses estratégicos como potencial transformador para modificar las relaciones de género, y las estructuras de subordinación. Activar políticas y medidas específicas para 
lograr la igualdad, con una planificación y evaluación de los resultados, es uno de los objetivos nacionales, y se incorpora la perspectiva de género y las políticas de equidad en todas las actividades (Subiñas, 2007). Este avance va a suponer un factor clave en el emprendimiento de las mujeres retornada, ya que estas se convierten en agentes de transformación, mediante acciones individuales o formando parte de estructuras en diversos ámbitos del emprendimiento. En este ámbito, el turismo es una actividad importante en la economía mundial por el dinamismo y la capacidad de desarrollo que tiene, dos aspectos ligados al proceso del cambio de la matriz productiva ecuatoriana, convirtiéndose en uno de los ejes con potencial para el desarrollo económico. Sin embargo, en los estudios de ESPOL (2015), no figuran cifras de emprendimientos productivos de mujeres migrantes retornadas en el sector turístico. Concretamente, el turismo sostenible es un área que aún no se ha explotado lo suficiente en el Ecuador y, en especial, en la ciudad de Machala - El Oro, siendo el espacio en el que pueden intervenir las mujeres migrantes retornadas.

\section{OBJETIVOS Y METODOLOGÍA}

El primer objetivo es descubrir las perspectivas que ofrece el sector turístico con una hipótesis de partida que afirma que este ofrece amplias oportunidades de progreso laboral a las mujeres retornadas. La metodología cuantitativa utiliza el análisis documental y descriptivo de los recursos turísticos naturales poco explotados, los paisajes culturales como imágenes de destino, y el número de visitantes que frecuentan los cantones de la Provincia de El Oro en 2017 y 2018 respectivamente ${ }^{1}$. Los datos de la Provincia fueron obtenidos a través de entrevistas efectuadas a los funcionarios de las Unidades y Departamentos de promoción y difusión turística de las áreas municipales de los cantones de la Provincia de El Oro ${ }^{2}$, que sirvieron para la confección de las Tablas 1 y 2. A partir de aquí se reproduce la realidad del contexto socioeconómico y de desarrollo social donde van a participar las mujeres retornadas, a través del emprendimiento y la empleabilidad en las distintas actividades económicas turísticas.

El segundo objetivo pretende indagar la integración de mujeres retornadas con potencial formativo, experiencia laboral consolidada y capacidad adquisitiva alcanzada en los sectores turísticos de mayor dificultad, y las trayectorias vitales que han tenido que atravesar. La metodología empleada ha sido la cualitativa a través de dos Focus Groups a mujeres retornadas desde España y otros países (ocho mujeres en cada grupo), que se encuentran realizando actividades remuneradas en el sector turístico hotelero, en restaurantes, agencias de viajes, centros turísticos y otros servicios de emprendimiento particulares. La muestra selectiva de mujeres participantes en los grupos abarca mujeres propietarias de restaurantes, empleadas, cajeras, y camareras en hoteles de las ciudades y de los centros turísticos. Los Focus Groups ${ }^{3}$ han sido desarrollados a través de la convocatoria previamente generada con el propósito de reunirlas en un punto determinado, cuestión que presenta dificultades acudiendo a la teoría de las recompensas

\footnotetext{
${ }^{1}$ Cantón: entidad territorial de carácter subnacional. La provincia de El Oro está dividida en 14 cantones: Arenillas, Atahualpa, Balsas, Chilla, El Guabo, Huaquillas, Las Lajas, Machala, Mar Cabeli, Pasaje, Portovelo, Santa Rosa y Zaruma.

${ }^{2}$ Datos obtenidos por Miguel Ángel Ramón Pineda (Prof. de la Universidad de Machala y doctorando de la Escuela Internacional de Doctorado de la UNED en el Programa Análisis de los Problemas Sociales), realizadas en el mes de noviembre de 2019.

${ }^{3}$ Llevados a cabo por el profesor Ramón Pineda los días 2 y el 7 de febrero de 2019 en la Ciudad de Machala Provincia de El Oro (Ecuador).
} 
basadas en los incentivos: "su propósito consiste en reconstruir la realidad, tal como la observan los actores de un sistema social previamente definido" (Valdiviezo, 2018: 20).

\section{TURISMO EN LA PROVINCIA DE EL ORO: DIFICULTADES DE EMPRENDIMIENTO Y EMPLEABILIDAD EN MUJERES RETORNADAS}

En los años 1999 y 2000, la Provincia de El Oro se vio afectada por la situación económica, social y política que atravesaba el país, así que muchos de sus habitantes de ese momento, específicamente en Machala, emigraron hacia Estados Unidos, España e Italia. En el año 2001, aproximadamente 9.788 personas salieron del país y cinco de cada diez eran mujeres (INEC, 2010). La provincia se vio impactada por esta situación ya que no se contaba con mano de obra calificada para las actividades agrícolas, mineras, entre otras, que eran vitales para la provincia, y que por el fenómeno de migración ocurrido en la época, las actividades y los ingresos económicos derivados, se vieron afectados directamente.

La ciudad de Machala (Figura 1) es una ciudad altamente poblada y gran parte de sus habitantes no son originarios de la misma, muchos proceden de ciudades de la sierra y de provincias anexas como Loja y Azuay las cuales vienen a la urbe Machaleña en busca de una mejor calidad de vida enfrentándose a drásticos cambios, e incluso llegando a ser víctimas de discriminación en un mundo muchas veces desconocidos para ellos. A partir del año 2010, los ecuatorianos que emigraron comenzaron a regresar en una buena parte de los casos, contribuyendo a la reactivación de la economía de la provincia y del país, y aportando nuevos conocimientos y técnicas para mejorar los procesos de producción, y obtener mejores beneficios.

Figura 1: Los 14 cantones de la Provincia de El Oro (Ecuador) y mapa físico

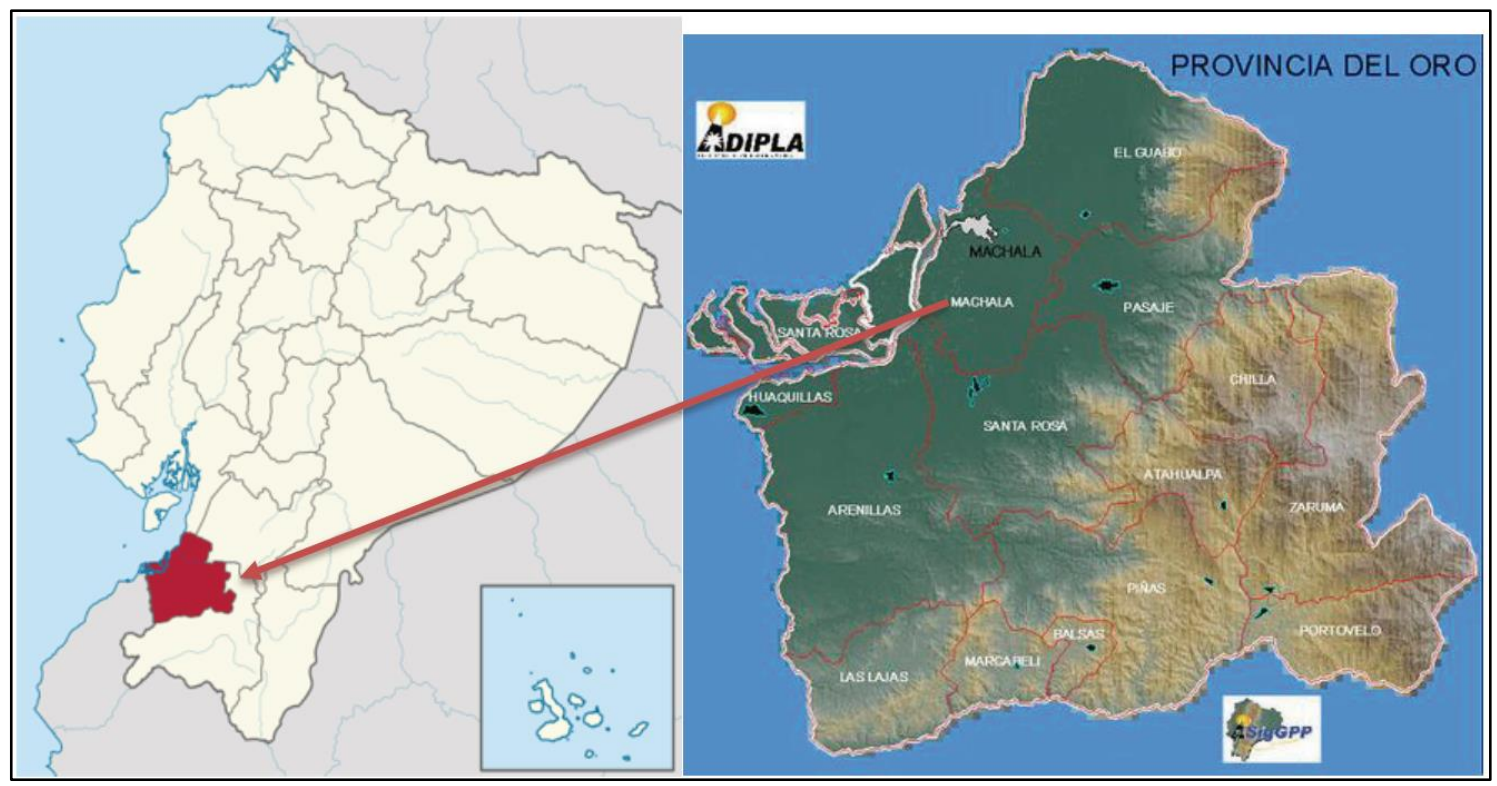

Fuente: elaboración propia a partir de Wikipedia.

El potencial turístico en la Provincia de El Oro es importante y revierte en distintas consecuencias económicas que dinamizan el desarrollo local, dependiendo 
principalmente de los factores sociales, políticos, geográficos, económicos, culturales y de la globalización (Serrano y Villafuerte, 2017). Pese al obstáculo que conlleva la financiación para el emprendimiento, se detectan otros aspectos positivos que coadyuvan a impulsar este tales como la motivación, la experiencia, la persistencia y las oportunidades de mercado (García et al., 2016). En este contexto, se aprecian dos tipologías de turismo en la Provincia de El Oro: el turismo tradicional y el turismo alternativo.

El turismo tradicional es masivo y pertenece a las primeras etapas de despegue del turismo que apuesta por el desarrollo, momento en el que se exploran los parajes casi vírgenes que apenas cambian y se dota de infraestructuras y servicios necesarios, donde se dan los primeros pasos para las relaciones sociales y la transformación (Martínez-Quintana, 2019). En la perspectiva de América Latina, y más concretamente las políticas turísticas y de medio ambiente en México, se disgrega el turismo en dos grandes bloques, el turismo tradicional y el turismo alternativo, de aquí surgen definiciones como la de Ibáñez y Rodríguez (2012, p. 18) que, a su vez, toman del barómetro mundial de la OMT de 2005 una conceptualización del turismo tradicional como un turismo de masas en el que se desarrollan grandes instalaciones turísticas y hábitos de consumo que demandan servicios sofisticados, la visita a la playa y la disponibilidad de grandes destinos turísticos o ciudades de atractivo cultural.

En nuestro caso, el turismo tradicional en la Provincia de El Oro se encuentra repartido en los siguientes lugares turísticos: El Balneario Jambelí, La Isla del Amor, El Balneario El Coco, el Balneario Bajo Alto, la Isla San Gregorio, El Puerto La Pitaya y el Puerto Jelí. En la Tabla 1, se observa el incremento de visitantes del año 2017 y 2018, pasando de 239.000 a 292.000 turistas, siendo el Balneario Jambelí (46 \% y 41,1 \%) el destino turístico que más turistas recibió, seguido de El Balneario del Bajo Alto $(25,1 \%$ y $24 \%)$ y el Puerto Jelí (16,8 \% y 20,5\%) respetivamente. El resto de los lugares turísticos siguen esa tendencia de ascenso a excepción de La Isla del Amor que se mantiene igual, mientras que el destino que más visitantes ha recibido de un año a otro ha sido El Puerto de Jelí que pasa de 40.000 visitantes a 60.000 respectivamente.

Tabla 1: Visitantes en las áreas del turismo tradicional de La Provincia de EI Oro

\begin{tabular}{|c|c|c|c|c|c|}
\hline \multirow{2}{*}{$\begin{array}{c}\text { Lugares con } \\
\text { potencial turístico }\end{array}$} & \multicolumn{2}{|c|}{2017} & \multicolumn{2}{|c|}{2018} & \multirow{2}{*}{ Fuente } \\
\hline & Turistas & $\%$ & Turistas & $\%$ & \\
\hline El balneario Jambeli $* * *$ & 110.000 & $46 \%$ & $120.000(+)$ & $41.1 \%$ & $\begin{array}{l}\text { Unidad de promoción difusión } \\
\text { turística del GAD Parroquial de } \\
\text { Jambeli }\end{array}$ \\
\hline La isla del Amor & 5.000 & $2.1 \%$ & $5.000(=)$ & $1.7 \%$ & $\begin{array}{l}\text { Unidad de promoción difusión } \\
\text { turística del GAD Parroquial de } \\
\text { Jambeli }\end{array}$ \\
\hline El balneario El Coco & 20.000 & $8.4 \%$ & $30.000(+)$ & $10.2 \%$ & $\begin{array}{c}\text { Unidad administrativa del } \\
\text { Balneario El Coco - Machala }\end{array}$ \\
\hline $\begin{array}{l}\text { El Balneario Bajo } \\
\text { Alto** }\end{array}$ & 60.000 & $25.1 \%$ & $70.000(+)$ & $24 \%$ & $\begin{array}{l}\text { Unidad de promoción difusión } \\
\text { turística del GAD Municipal del } \\
\text { Cantón El Guabo }\end{array}$ \\
\hline La Isla San Gregorio & 2.000 & $0.8 \%$ & $4.000(+)$ & $1.3 \%$ & $\begin{array}{c}\text { Unidad de promoción difusión } \\
\text { turística del GAD Municipal del } \\
\text { Cantón Huaquillas }\end{array}$ \\
\hline El Puerto La Pitaya & 2.000 & $0.8 \%$ & $3.000(+)$ & 1.02 & $\begin{array}{l}\text { Departamento de turismo del GAD } \\
\text { Municipal del cantón Arenillas }\end{array}$ \\
\hline El Puerto Jelí* & 40.000 & $16.8 \%$ & $60.000(+)$ & $20.5 \%$ & $\begin{array}{l}\text { Departamento de turismo del GAD } \\
\text { Municipal del cantón Santa Rosa }\end{array}$ \\
\hline Total & 239.000 & $100 \%$ & $292.000(+)$ & $100 \%$ & \\
\hline
\end{tabular}

Fuente: Elaboración propia. *Prelación en el crecimiento del número de turistas. 
Siguiendo el orden de lugares más visitados figura en primer lugar Jambeli, que es una isla que forma parte de la tradición turística de la Provincia de El Oro. Su posicionamiento a nivel nacional, con influencia del norte del Perú, hace que sea un destino permanente para los turistas. Cuenta con una excelente infraestructura hotelera y oferta gastronómica con la consecuente empleabilidad y emprendimiento que ello conlleva, y un referente de riquezas marinas que tiene en su haber experiencias excepcionales. El segundo lugar es el Bajo Alto, su reserva natural le dota de un potencial turístico único para el entretenimiento y la gastronomía, que son impulsados por nuevos emprendedores. En tercer lugar, Puerto Jelí, sus características principales son la gastronomía de productos del mar, la gastronomía alternativa (seco de pato y de chivo), las plantaciones de cítricos y la observación de aves.

Los cuatro destinos restantes tienen también su relevancia, con unas peculiaridades que les hace exclusivos, así tenemos El balneario El Coco situado en el filo costero de Machala y Puerto Bolívar, lugar que acoge a los visitantes que desean visitar sus playas y aguas relajantes. La isla del Amor, a 20 minutos en embarcación desde Puerto Bolívar, es una isla que todavía no ha sido explotada, su riqueza está marcada por la flora compuesta por el bosque de mangle, rojo, salado y negro, además está la fauna, con una gran diversidad de aves: pelícanos, garzas blancas y grises, fragatas, etc. Destaca también San Gregorio que es una isla del archipiélago de Jambelí, ubicado a una hora del Puerto de Hualtaco, cantón Huaquillas. Es un área que permanece en estado natural, y que aún no ha sido explotada. Las condiciones ambientales, flora y fauna son casi similares a los otros sitios de la franja costera, sin embargo lo que caracteriza a esta isla, es la calidez de sus aguas, la amplitud de sus playas y la arena blanquecina. Aquí la producción de concas y mejillones son un atractivo que también puede ser aprovechado para el emprendimiento turístico. La superficialidad del canal de acceso limita la actividad turística que, por otra parte, la convierte en una lugar para el esparcimiento alejada del bullicio de la ciudad y de los otros centros, y deseable para los visitantes que desean vivir nuevas experiencias.

Por último, La Pitaya, un puerto con recursos turísticos con paisajes majestuosos de campos poblados de banano, cultivos de arroz, cacao, cítricos como naranja, limón y mandarinas. Mención especial merece Puerto Bolívar, Parroquia Urbana de Machala, que es el lugar de embarque y desembarque de los turistas que visitan los balnearios en las islas como Jambeli, que registra una gran movilidad y dinamismo económico apto para los emprendimientos turísticos. La gastronomía con productos del mar, y los centros de entretenimiento nocturno son atractivos turísticos de gran éxito.

El segundo bloque de turismo de la Provincia de El Oro es el turismo alternativo, que es más selectivo y se corresponde con etapas del turismo posteriores al de masas. Está comprendido de varios turismos que se combinan entre sí como el turismo cultural, el turismo rural, el agroturismo, el ecoturismo, el turismo de aventura y el turismo cinegético, que en su conjunto forman el turismo de interior. El turista participa en actividades recreativas de contacto con la naturaleza y con las comunidades rurales, y respeta los patrimonios naturales, culturales e históricos del lugar que visita (Ibañez y Rodríguez, 2012). En la Provincia de El Oro el turismo alternativo abarca los siguientes lugares turísticos: Ciudad de Zaruma, Ciudad de Piñas, Ciudad de Portovelo, Bosque petrificado de Puyango, Reserva ecológica Arenillas (Florecimiento de los guayacanes), Reserva ecológica Buenaventura, Cantón Santa Rosa - balnearios Limón Playa, Complejo arqueológico Yacuviñay, y Cantón Pasaje - balnearios: Chaguana, Las Cadenas, La Cocha, Chaguana.

En la Tabla 2 figuran los visitantes a las áreas de turismo alternativo en la Provincia de El Oro, que registra entre 2017 y 2018 un descenso en el número de visitantes, ya que 
pasa de tener 243.000 turistas a 222.378 respectivamente, una pérdida de 20.622 visitantes. Los lugares turísticos que pierden flujos turísticos de un año a otro son por orden de prelación: Cantón Santa Rosa- balnearios Limón Playa (37 \% y 36,1 \%), Cantón Pasaje - Balneario Chaguana, Las Cadenas, La Cocha, Chaguana (28,8 \% y 22,5 \%), Bosque petrificado de Puyango (6,2 \% y 5,8 \%), Ciudad de Portovelo (1,5 \% y 1,3\%) y Ciudad de Zaruma (1,2\% y 1,2 \%) respectivamente en 2017 y 2018.

En contraposición, los lugares turísticos que ganan flujos de visitantes por orden de prelación son Reserva ecológica Buenventura (20,6 \% y 24,7 \%), Reserva ecológica Arenillas (Florecimiento de los guayacales) (3,3\% y 5,4 \%), complejo arqueológico Yacuviñay $(0,8 \%$ y $2,2 \%)$ y Ciudad de Piñas $(0,6 \%$ y $0,8 \%)$, respectivamente en 2017 y 2018. En suma, se aprecia que hay cinco destinos turísticos que pierden turistas, entre los que destaca el Cantón Pasaje con 20.000 visitantes menos y Bosque petrificado con 2.000 visitantes menos. Respecto a los que ganan visitantes, sobresalen la Reserva ecológica Buenaventura, con 5.000 visitantes más; la Reserva ecológica Arenillas, con 4.000 visitantes más; y el Complejo arqueológico Yacuviñay, con 3.000 visitantes más. Son los destinos únicos y naturales los que más afluencia de turistas tienen, y es una modalidad de destinos que pertenecen fundamentalmente al turismo de naturaleza.

Tabla 2. Visitantes en las áreas de turismo alternativo de La Provincia de El Oro

\begin{tabular}{|c|c|c|c|c|c|}
\hline \multirow{2}{*}{$\begin{array}{c}\text { Lugares con potencial } \\
\text { turístico }\end{array}$} & \multicolumn{2}{|c|}{2017} & \multicolumn{2}{|c|}{2018} & \multirow{2}{*}{ Fuente } \\
\hline & Turistas & $\%$ & Turistas & $\%$ & \\
\hline Ciudad de Zaruma & 3.000 & $1.2 \%$ & $2.728(-)$ & $1.2 \%$ & $\begin{array}{l}\text { Unidad de promoción difusión } \\
\text { turística del GAD Municipal del } \\
\text { cantón Zaruma }\end{array}$ \\
\hline Ciudad de Piñas & 1.500 & $0.6 \%$ & $1.750(+)$ & $0.8 \%$ & $\begin{array}{l}\text { Departamento de turismo del } \\
\text { GAD Municipal del cantón } \\
\text { Piñas }\end{array}$ \\
\hline Ciudad de Portovelo & 3.500 & $1.5 \%$ & $2.900(-)$ & $1.3 \%$ & $\begin{array}{c}\text { Departamento de turismo del } \\
\text { GAD Municipal del cantón } \\
\text { Portovelo } \\
\end{array}$ \\
\hline $\begin{array}{l}\text { Bosque petrificado de } \\
\text { Puyango** }\end{array}$ & 15.000 & $6.2 \%$ & $13.000(-)$ & $5.8 \%$ & $\begin{array}{c}\text { Oficina de registros turísticos - } \\
\text { B P Puyango }\end{array}$ \\
\hline $\begin{array}{c}\text { Reserva ecológica } \\
\text { Arenillas (Florecimiento } \\
\text { de los guayacanes) } \\
\end{array}$ & 8.000 & $3.3 \%$ & $12.000(+)$ & $5.4 \%$ & $\begin{array}{c}\text { Departamento de turismo del } \\
\text { GAD Municipal del cantón } \\
\text { Arenillas }\end{array}$ \\
\hline $\begin{array}{c}\text { Reserva ecológica } \\
\text { Buenaventura } *\end{array}$ & 50.000 & 20.6 & $55.000(+)$ & $24.7 \%$ & $\begin{array}{l}\text { Secretaria Técnica Distrital de } \\
\text { turismo de El Oro }\end{array}$ \\
\hline $\begin{array}{c}\text { Cantón Santa Rosa - } \\
\text { balnearios Limón Play*** }\end{array}$ & 90.000 & $37 \%$ & $80.000(-)$ & $36.1 \%$ & $\begin{array}{c}\text { Departamento de turismo del } \\
\text { GAD Municipal del cantón } \\
\text { Santa Rosa } \\
\end{array}$ \\
\hline $\begin{array}{c}\text { Complejo arqueológico } \\
\text { Yacuviñay }\end{array}$ & 2.000 & $0.8 \%$ & $5.000(+)$ & $2.2 \%$ & $\begin{array}{l}\text { Departamento de turismo del } \\
\text { GAD Municipal del cantón } \\
\text { Chilla }\end{array}$ \\
\hline $\begin{array}{c}\text { Cantón Pasaje - } \\
\text { Balnearios: Chaguana, } \\
\text { Las Cadenas, La Cocha, } \\
\text { Chaguana** }\end{array}$ & 70.000 & $28.8 \%$ & $50.000(-)$ & $22.5 \%$ & $\begin{array}{l}\text { Departamento de turismo del } \\
\text { GAD Municipal del cantón } \\
\text { Pasaje }\end{array}$ \\
\hline Total & 243.000 & $100 \%$ & $222.378(-)$ & $100 \%$ & \\
\hline
\end{tabular}

Fuente: elaboración propia. *Prelación en la pérdida del número de turistas.

En definitiva, el potencial del turismo alternativo se basa en su patrimonio natural y su biodiversidad, que está patente en todos los lugares de la Provincia de El Oro, y entre los lugares que han perdido flujos de turistas en estos dos años de observación, se sitúa en primer lugar el Cantón Santa Rosa (-) que tiene los balnearios Limón Playa, sitios 
gastronómicos como la comunidad de Jumon y Puerto Jeli y el aeropuerto internacional. Es un cantón que reúne las condiciones propicias para el emprendimiento productivo turístico de las mujeres retornadas de España y otros países, y ha sido objeto de estudio para conocer los gustos, las preferencias y los hábitos de viaje del turista, así como los criterios técnicos en la planificación de la inversión pública y privada, y en la creación, innovación o especialización de productos turísticos (Sandoval et al., 2018).

En segundo lugar, el Cantón Pasaje (-) con balnearios de agua dulce como el de Chaguana, Las Cadenas, La Cocha y el río Buena Vista, son muy concurridos en días feriados y fines de semana. En tercer lugar, El bosque petrificado de Puyango (-) en el Cantón Las Lajas, con un área de 2.658 hectáreas que atrae a turistas nacionales y extranjeros por sus recursos vegetales petrificados y el exuberante paisaje natural. Sus senderos bien organizados brindan la oportunidad de apreciar los restos de árboles petrificados del género araucaria de hasta 15 metros, que datan de aproximadamente 100 millones de años. La vegetación fosilizada se complementa con aves de fácil avistamiento: las pacharacas, perdiz, el tordo, etc. También se encuentran los monos aulladores que son endémicos de la zona. Además de la vegetación en estado natural como el Pretino de alrededor de 8 metros de diámetro y unos 35 metros de altura con una edad aproximada de 300 años. Este bosque es uno de los más extensos junto al de la Patagonia y Arizona.

Por último, los cantones de Zaruma (-) y Portovelo (-), que poseen un patrimonio cultural muy valioso constituido y enriquecido en cada época con un conjunto de atractivos como paisajes, minería histórica y arquitectura (Villafuerte et al., 2015). El caso de Zaruma es digno de mención por ser un cantón con recursos turísticos que pertenecen al patrimonio de la humanidad, y requiere medios imprescindibles para su preservación (Rodríguez et al., 2013). Allí se encuentra la arquitectura colonial de corte barroco, en una ciudad de calles estrechas y empinadas, la calidez de sus gentes y los rastros de la minería del siglo XIX, que en temporada alta se registraron en la unidad de turismo de esta dependencia, 12.550 turistas, cubriendo el $100 \%$ de la capacidad hotelera, según datos del área municipal de Zaruma. El turismo basado en los recursos y unidades de producción minera, al igual que Zaruma, lo comparte el cantón Portovelo, con un legado incaico, donde el paisaje está colmado de una exuberante vegetación y supone un gran atractivo turístico.

Los lugares que han ganado flujos de turistas en el turismo alternativo de la Provincia de El Oro tienen, al igual que las anteriores, buenas perspectivas de desarrollo local a través del emprendimiento y la empleabilidad, unido a unas políticas turísticas que respeten el medio ambiente. Sobresale la reserva ecológica Buenaventura (+) con 1.600 hectáreas de bosque natural, en la que se practica el turismo de aventura. Es un área ecosistémica que alberga alrededor de 300 especies de aves y 36 tipos de colibríes (Figura 2), monos, armadillo, guantas, venados, entre otros, los que son matizados con la belleza y esplender de sus orquídeas. La Reserva ecológica del Cantón Arenillas (+), tiene una gran variedad de flora y fauna, y despunta por el florecimiento de los Guayacanes al final o inicio de año, convirtiéndose en un espléndido atractivo turístico, con una impresionante biodiversidad de especies y matorrales que solo se encuentran en bosques con ecosistemas secos ecuatoriales (Figura 2). La serie de senderos permite moverse por la espesa vegetación que brinda la oportunidad de disfrutar del avistamiento de animales como el venado, las ardillas y la perdiz, entre otros (Martínez-Quintana et al., 2018).

El penúltimo es el complejo arqueológico Yacuviñay (+), denominado la ciudad perdida de los incas, en el Cantón Atahualpa. Es un atractivo turístico que despierta la atención por sus vestigios representados en los muros de lo que habrían sido un asentamiento indígena en tiempos del incario (Figura 2). Y la última, Piñas (+) que representa el simbolismo de la región interandina de corte costeño, en la que el calor humano y la 
amabilidad de sus gentes contrasta con el frio de su clima; se la conoce como la orquídea de los andes, y su población desarrolla gran capacidad para el emprendimiento y la empleabilidad que liderarán, entre otros, la población de mujeres retornadas con poder adquisitivo.

Figura 2: Paisajes culturales de colibríes -reserva ecológica Buenaventura-, los Guayacanes reserva ecológica de Arenillas- y La ciudad perdida de los Íncas como productos turísticos

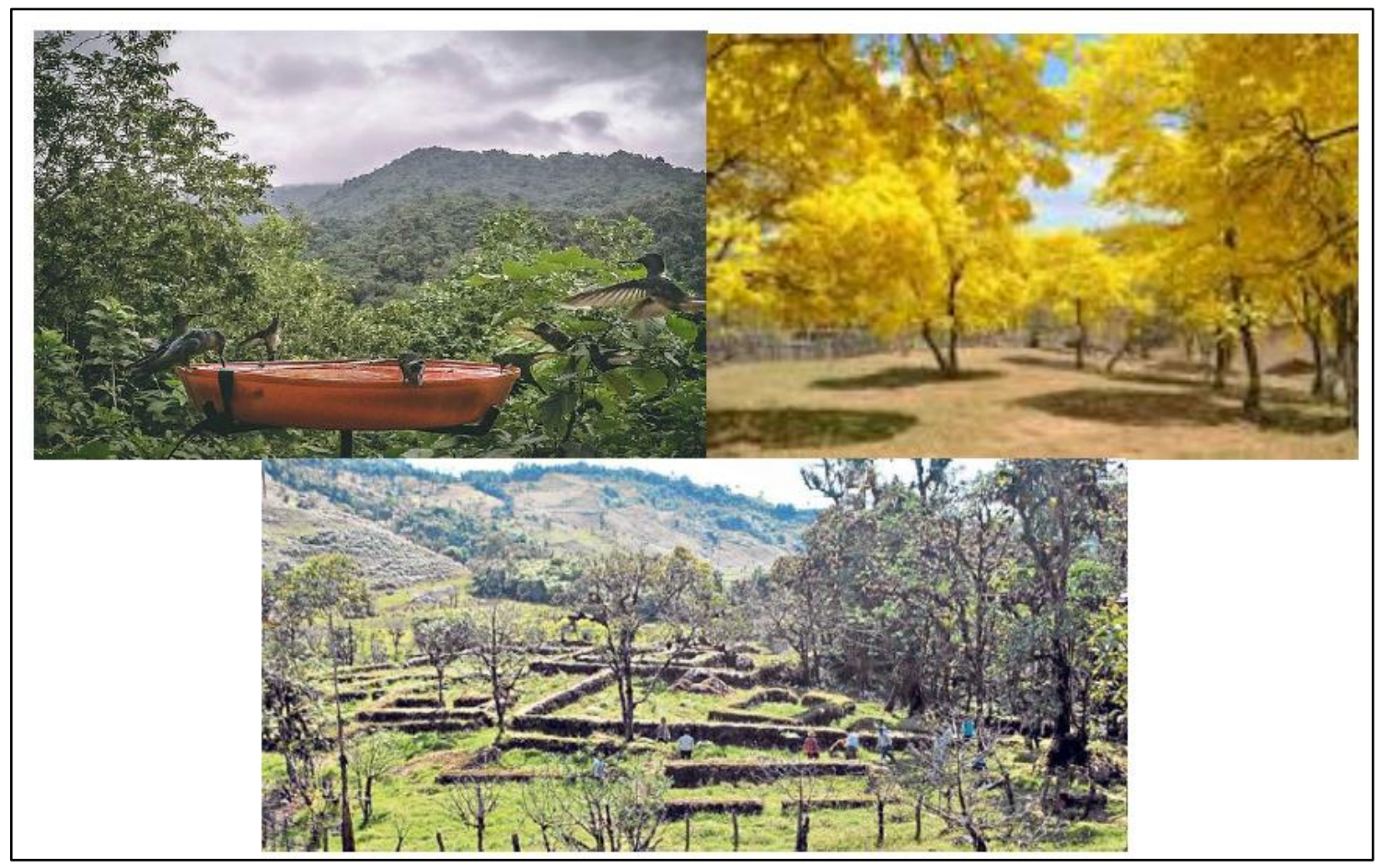

Fuente: adaptado de las imágenes de la zona de la reserva ecológica Buenaventura, y de la zona del complejo arqueológico Yacuviñay.

Como se muestra, existe un enorme potencial en la zona rural de la Provincia de El Oro para el emprendimiento de las mujeres retornadas, que pueden participar especialmente en el desarrollo local con el turismo de naturaleza. Los lugares donde tienen mejores posibilidades para el emprendimientos y la empleabilidad en el sector turístico son diversos, y en su mayoría, se sitúan en el contexto rural. La ciudad por su naturaleza se ha convertido en un ámbito de alta contaminación auditiva, visual, y medioambiental que afecta a todo el entorno urbano, lo que hace que el residente busque nuevas alternativas de oxigenación y de esparcimiento ante la vida moderna estresante, y busque en las zonas rurales y costeras el contacto con la naturaleza, que es el principal valor patrimonial de la Provincia de El Oro, ya que:

\footnotetext{
"el turismo de naturaleza supone una enorme oportunidad de contactar con las raíces naturales y saludables que las personas necesitan en los hábitats en los que conviven, y puede actuar de compensación ante la 'comodidad' del hábitat urbano polucionado y su ritmo de vida estresante" (Martínez-Quintana, 2017:2).
}

De ahí que la diversidad turística en las zonas rurales debe ser motivo de mayor atención como espacio para la generación de empleos femeninos. Esta variedad en la actividad 
turística ha generado un cambio de percepción del entorno medioambiental, considerándolo un recurso valioso que ha de cuidarse. La población urbana, dispuesta a consumir este producto y a pagar por disfrutar de tranquilidad, armonía, belleza y tradición, es el factor generador de nuevas rentas que fluyen hacia la población autóctona rural. Además, las condiciones topográficas que limitan el uso agrario de los territorios aumentan su valor para el turismo de naturaleza, por lo que la población local obtiene nuevos usos y rendimientos económicos de la tierra, reduciendo el fenómeno migratorio en el medio rural. Así, el turismo en el ámbito rural se convierte en una actividad complementaria en la generación de rentas gracias a la plurifuncionalidad de los espacios rurales (Millán et al., 2015; Ferreres y Querol, 2019).

¿Cuáles son, pues, los sectores de mayor dificultad para la empleabilidad de las mujeres retornadas? En ciertas ofertas de empleo se advierte que no se especifica el género, pero en cambio hay otras ofertas en las que se detalla con claridad que es un empleo de azafata, camarera en hostelería, cocinera en gastronomía o secretaria en agencias de viaje. De cara a la empleabilidad de las mujeres retornadas, uno de los sectores turísticos que presenta mayor dificultad es el turismo de aventura. Este comportamiento se explica porque los hombres generalmente poseen unas características personales que no se encuentran en las mujeres (Pastor y Martínez, 1991), y se hace patente cierta exclusión social hacia la mujer que aún persiste, y que la aleja de ciertas actividades. De hecho, no se registran datos de la inserción laboral de la mujer como guía en el turismo de aventura, teniendo en cuenta que Ecuador compite como destino mundial de aventura (Montoya, 2015).

En la reserva ecológica Buenaventura existen tres guías turísticos, de los que dos son hombres y una es mujer. Generalmente, los senderos con mayores dificultades son tomados por los hombres en la mina turística. En la ciudad de Zaruma existe un guía de sexo masculino que es quien orienta a los turísticas hasta aproximadamente 600 metros de profundidad, aquí no existe presencia femenina. En el Bosque Petrificado de Puyango existen tres personas, dos hombres y una mujer; en la cooperativa de transporte fluvial Rafael Moral Valverde que moviliza turistas hacia la isla Jambeli, los operadores son hombres, y son datos que muestran las dificultades a las que tienen que enfrentarse las mujeres, especialmente cuando se trata de áreas turísticas que exigen esfuerzo físico.

La hipótesis de partida afirmaba que el sector turístico ofrece amplias oportunidades de progreso laboral a las mujeres retornadas, hipótesis que en parte se confirma según las características turísticas patrimoniales que se encuentran en desarrollo y explotación en los cantones de la Provincia de El Oro. Sin embargo, las experiencias vertidas en las narrativas de las mujeres inmigrantes retornadas que han participado en los Focus Groups, detectan obstáculos en el progreso laboral por cuestiones de género, desigualdad y discriminación, que se plasman en la sobrerrepresentación y subrepresentación que padecen en la empleabilidad y en el emprendimiento vinculantes al turismo tradicional y alternativo de esta Provincia de Ecuador. Los dos Focus Groups de nuestra investigación desdoblan dos áreas en las que se desarrollan laboralmente, como muestra la Tabla 3, a saber: recepcionistas y camareras en hoteles, empleadas en restauración y propietarias de restaurantes de los puertos como el de Jelí y Hualtaco, que corresponden al turismo tradicional fundamentalmente. Las participantes de los dos Focus Groups en su integración al mundo laboral, coinciden que el emprendimiento en el sector turístico es una actividad muy favorable y con perspectivas de futuro, así lo ratifican al preguntarles: ¿cree que las mujeres emprendedoras en el sector turístico ofrecen actividades muy favorables y con oportunidades de inserción laboral? A este respecto consideran que existe un gran potencial y es favorable debido a que la Provincia de El Oro y Machala, están ubicadas en la zona de frontera, eso permite generar una intensa movilidad que es 
aprovechada por el sector hotelero. También está la riqueza turística de los balnearios de los ríos de agua dulce y la zona costera, lo que aumenta las expectativas para que las mujeres se inserten laboralmente como dependientes o autónomas.

Tabla 3. Emprendimiento y empleabilidad de las mujeres retornadas en la Provincia de El Oro

\begin{tabular}{|c|c|}
\hline $\begin{array}{l}\text { Focus Group } 1 . \\
\text { Empleabilidad }\end{array}$ & $\begin{array}{l}\text { "Trabajo como recepcionista en un hotel de Jámbela" (E1). } \\
\text { "Laboro como camarera en el Hillary resort" (E2). } \\
\text { "Arriendo los departamentos en la playa de Jámbela (E3). } \\
\text { "Trabajo como camarera en Puerto Bolívar en un restaurante" (E4). } \\
\text { "Tengo un restaurante en puerto Jelî́" (E5). } \\
\text { "Trabajo de recepcionista en un hotel de Puerto Bolívar" (E6). } \\
\text { "Yo también trabajo de recepcionista en un hotel de Puerto Bolívar" (E7). } \\
\text { "Trabajo de recepcionista en un complejo turístico del balneario la Cocha (E8). }\end{array}$ \\
\hline $\begin{array}{l}\text { Focus Group } 2 . \\
\text { Emprendimiento }\end{array}$ & $\begin{array}{l}\text { "Trabajo de mesera* en el Hillary" (E1). } \\
\text { "Tengo un restaurante propio aquí en Puerto Hualtaco" (E2). } \\
\text { "Soy camarera en puerto Jelí" (E3). } \\
\text { "Administro un hotel aquí en el banco de Huaquillas" (E4). } \\
\text { "Actualmente tengo lo que es un restaurante propio en puerto Hualtaco" (E5). } \\
\text { "Igualmente tengo una picantería* en lo que es este puerto Jelî́ (E6). } \\
\text { "Yo tengo mi negocio propio vendiendo artesanías en la isla San Gregorio" (E7). } \\
\text { "Tengo una cevichería* en Aguas Verdes Perú" (E8). }\end{array}$ \\
\hline
\end{tabular}

Fuente: elaboración propia. *Camarera; comida picante; restaurante.

En realidad, tal y como las mujeres retornadas lo expresan, las dificultades de la reinserción laboral se encuentran con las limitaciones de un país no muy extenso, pero con un potencial por explotar en el que no se apuesta todavía por el desarrollo a gran escala:

\footnotetext{
"Realmente el turismo si es una actividad muy productiva, si hablamos de las mujeres en futuro, yo creo que tenemos un gran campo para una inserción laboral favorable en esta área (...) Desde el punto de vista realista, nuestro país es un poco difícil para la inserción laboral en alguna área ¿por qué? Porque no somos un país tan grande como los países europeos, pero tenemos la ventaja de que Ecuador es un lugar que tiene una biodiversidad inmensa, solo tenemos que buscar los lugares estratégicos donde nosotras podemos trabajar" (F. G.1: E4).

“Tengo un restaurante y lo hice con lo poco que traje de España, pero me falta más economía para abrirme un poco más en mi país. A mí me interesaría poner un centro turístico aquí en Huaquillas o más adelante de Huaquillas, necesitaría unas dos hectáreas de terreno para ponerme el restaurante con piscina, un centro turístico que sea para el Ecuador, para Huaquillas” (F.G. 2: E8).
}

Las ventajas comparativas con respecto a otros sectores que les ha impulsado a incorporarse laboralmente en el área del desarrollo turístico, se basan en el encanto personal y la capacidad de tener relaciones personales, tener otros valores añadidos por la experiencia obtenida en otros países, tener la puntualidad, empatía con los turistas que llegan, y el conocimiento de las costumbres del propio país de acogida, lo que enriquece su capacidad para alternar ambas culturas. Así manifiestan sus opiniones:

"Una ventaja también es que cuando se va a los países europeos se adquieren otros valores, valores como la puntualidad, el respeto que es muy importante... y creo que cuando se regresa para acá 
siempre se tiene presente por más que aquí no se respete, es como un punto a favor, sobre todo para las mujeres que quieren invertir aquí, poner un negocio como es el turismo; un negocio muy respetado en la actualidad" (F.G. 1: E2).

“Otra ventaja y punto a favor es el conocimiento que tenemos de las áreas turísticas tanto del país de acogida como del país de origen... tenemos la capacidad de conocer ambos lados, dar varias opiniones o varios aspectos según las experiencias de bastantes años vividos fuera... nosotras podemos compartir, podemos tener esa empatía con las personas al llegar a lo que es en este momento nuestra área turística" (F.G. 1: E4).

Las entrevistadas tienen consideraciones favorables con respecto al área turística, no obstante hay mayor dificultad de unos sectores a otros, al estar sin desarrollar en su totalidad, y más bien en proceso de desarrollo. Se les consultó si consideran que el área turística presenta muchas oportunidades de inserción laboral (empleabilidad y emprendimiento) para las mujeres migrantes retornadas desde España u otros países. De las respuestas obtenidas se desprende que, en general, ellas perciben dificultades por las limitaciones de un país que no es muy extenso, pero que tiene recursos naturales de gran potencial todavía sin explotar en sus variadas formas, a excepción del turismo tradicional que se encuentra en pleno despegue:

\begin{abstract}
"Debe enfocarse donde más le resulte la economía, porque Machala el Oro posee varios lugares que no se han descubierto todavía las bellezas que posee. Nosotras como mujeres emprendedoras con otra mentalidad, venimos de otros países, y enfocamos el emprendimiento en lo que le conviene para invertir, y poder desarrollarse como persona y con una economía básica e imprescindible” (F. G. 1: E2).

"Yo pienso que el área turística es una de las áreas que más genera economía, y genera a su vez trabajo, entonces para las mujeres que se reinsertan aquí en el Ecuador es muy beneficioso. La mayoría de los trabajos que se presentan en esta área son por cuenta ajena o están más relacionada con la labor que normalmente pueden desempeñar las mujeres" (F. G. 2: E7).
\end{abstract}

Una vez que se han integrado en el sector turístico se les cuestiona en qué han tenido mayor satisfacción, ya sea en lo económico, social, cultural o personal, para conocer sus trayectorias vitales. En este sentido, han obtenido oportunidades de crecimiento personal, cultural y de realización económica al tener las mujeres experiencia, conocimientos, habilidades culinarias, educación adquirida de los países de destino en los que trabajaron durante años, y que ahora pueden rentabilizar:

\footnotetext{
"Yo creo que si porque venimos de otros países y ya tenemos más experiencia en lo que es trabajar... los ecuatorianos somos más educados yo creo que viendo a otras personas de otros países, es lo que muchas veces admiran de los ecuatorianos que somos mucho más educados que los de otros países, porque en el Ecuador tenemos lo que es saludar o agradecer por todo lo que viví en España... creo que nosotros somos más cariñosos al tratar a los turistas y por eso creo que se incrementa el turismo en el Ecuador y eso es muy bueno" (F.G. 1: E6).

"Yo pienso que el hecho de trabajar en el sector turístico nos permite a nosotras brindar un servicio hacia los turistas, el hecho de conocer, de brindar un poco de conocimiento acerca de lo que nosotras trajimos de otro país, otras costumbres, otras culturas, y al mismo tiempo conocer esas costumbres y culturas de otras personas que llegan a nosotras... personas que conocemos, nuevas experiencias, nuevos pensamientos, ideologías que nos sirven para crecer como personas principalmente"(F.G. 2 : E7).
} 
Finalmente, un rasgo característico en la trayectoria vital experimentada es la discriminación por la edad, el nivel educativo, el sexo, la etnia, la desigualdad en las oportunidades de inserción laboral, y en el desenvolvimiento del emprendimiento y de la empleabilidad en el sector turístico:

\begin{abstract}
"El turismo se enfoca más hacia los jóvenes adolescentes, porque pueden insertarse más, llaman la atención como quien dice... aunque suene feo, pero llaman la atención, y eso le gusta a la gente. Si tu tuvieras un negocio no vas a poner a una persona adulta a atender un negocio, siempre buscan una chica más o menos para que atraiga... es probable que suena mal, pero es así” (F.G. 1: E6).

"En nuestro país aún existe el estereotipo. Muchas en el regreso de España también conocieron la existencia del racismo allá... y nuestro país no se queda atrás. Por ejemplo si tú vas a buscar un trabajo en " $x$ " lugar, muchas veces si te ven bien "ok, no te preocupes por tu trabajo", pero tal vez si es una persona morenita no la llaman y nunca la llaman. Entonces yo pienso que sí que nuestro país aún tiene ese complejo de racismo" (F.G. 2: E3).
\end{abstract}

\title{
5. CONCLUSIONES
}

Las mujeres retornadas inmigrantes ecuatorianas han sufrido cambios importantes de abandono en las costumbres de una sociedad de origen, el Ecuador, viéndose forzadas a modificar sus patrones culturales del cuidado del hogar, la crianza y educación básica de los hijos para emprender actividades laborales de extenuante esfuerzo, y ajenas a su país de origen. Con el éxodo migratorio dejaron un vacío intermitente en sus familias para centrarse de pleno en tareas económicas que aportasen importantes beneficios, pagando así el coste de la ausencia ocasionada en sus familias en el lugar de origen.

El proceso de retorno coincide con un nivel de desarrollo económico a distintas velocidades de los países de acogida de donde provienen, especialmente de España. Son mujeres retornadas que tienen ahora un nivel formativo, una experiencia laboral y un poder adquisitivo que las capacita ante una reinserción laboral, y una vuelta al vacío familiar que dejaron en el momento de su partida o, en su caso, el inicio de una nueva vida. A partir de aquí, la incorporación a la sociedad se produce a través de la incorporación al mercado de trabajo que conlleva dificultades según los sectores económicos principalmente, inserción que va a estar liderada por el emprendimiento y la empleabilidad en el sector turístico.

El turismo con su dinamismo y capacidad de progreso se ha convertido en uno de los ejes potenciales para el desarrollo en el Ecuador, y aunque no figuran cifras de emprendimientos productivos de mujeres migrantes retornadas, se apunta al turismo sostenible como un área todavía sin explotar en los recursos naturales de la Provincia de El Oro. El contexto socioeconómico y de desarrollo local del sector turístico se caracteriza por la polarización del turismo tradicional y el alternativo, donde las mujeres retornadas están sobrerrepresentadas en el primero y subrepresentadas en el segundo.

De los dos Focus Groups realizados, se obtiene que en el primero existe una mayor empleabilidad, mientras que en el segundo predomina el emprendimiento. Las mujeres retornadas son recepcionistas, camareras de hoteles, empleadas en restauración y propietarias de restaurantes de los puertos como el de Jelí y Hualtaco, que corresponden al turismo tradicional fundamentalmente, si bien hay que tener en cuenta, según Moreno y Cañada (2018, p. 14) "la tremenda responsabilidad que tiene el sector turístico si pretende promover calidad y decencia en el empleo que genera". La integración al mundo 
laboral a través del emprendimiento en el sector turístico ha sido muy favorable y con perspectivas de futuro, y es un hecho que se ratifica en los dos grupos de mujeres retornadas. La Provincia de El Oro como zona de frontera tiene una intensa movilidad de personas, tanto en sus zonas costeras como en las del interior con un patrimonio natural y una biodiversidad destacables.

Las ventajas comparativas con respecto a otros sectores que les ha impulsado a incorporarse laboralmente por el desarrollo turístico se asientan en la formación, experiencial laboral y la capacidad adquisitiva lograda, y son elementos que se refuerzan con las cualidades innatas y las desarrolladas como el encanto personal, la capacidad de tener relaciones personales, poseer otros valores añadidos, puntualidad, conocimiento de otros países, y la empatía con los turistas que llegan.

Los sectores turísticos de mayor dificultad se encuentran en el turismo alternativo, y más concretamente, en el de aventura, como es el caso de las actividades que realizan las guías turísticas en las que prevalecen los hombres, al tratarse de áreas que exigen mayor esfuerzo físico según los requisitos de los empleadores. La dificultad proviene, en gran parte, por el nivel evolutivo en el que se encuentra el sector turístico en general, al hallarse en una etapa de despegue, en la que se apuesta por el desarrollo, se empiezan a explorar los parajes casi vírgenes y se dota de infraestructuras y servicios necesarios. Aquí las políticas turísticas todavía no se han desarrollado plenamente, como es el caso de las áreas de turismo alternativo en la Provincia de El Oro, que pese al potencia natural turístico perdió visitantes de 2017 a 2018. No ocurre lo mismo con el turismo tradicional que se encuentra en pleno despegue económico y social, y que proporciona muchas oportunidades de inserción laboral para las mujeres migrantes retornadas. La mayor satisfacción que alcanzan en sus trayectorias vitales la obtienen de haber obtenido oportunidades de crecimiento personal, cultural y de realización económica, y haber rentabilizado las experiencias previas obtenidas en su trayectoria vital como migrantes.

Por último, en las trayectorias vitales alcanzadas figuran la discriminación experimentada por la edad, el nivel educativo, el sexo, la etnia, la desigualdad en las oportunidades laborales de inserción al trabajo, y su impacto en el desenvolvimiento del emprendimiento y de la empleabilidad en el sector turístico, y es una realidad que obstaculiza su progreso laboral. Los estereotipos de género, las identidades y los roles tradicionales emergen en el imaginario colectivo, tanto en mujeres como en hombres. En consecuencia, se detecta la existencia del empoderamiento de las mujeres retornadas y la desigualdad en el sector turístico, cuando se produce, según Martínez-Quintana y Martínez-Gayo (2019) un crecimiento exponencial del turismo, en el que las mujeres se encuentran en un proceso anclado de discontinuos progresos y retrocesos con permanente sobrerrepresentación y subrepresentación en las categorías laborales, sin que se haya alcanzado todavía un ajuste necesario entre empoderamiento e igualdad.

\section{REFERENCIAS}

Alarcón, S., y Ordóñez, J. (2015). Ecuador: retorno migratorio y emprendimiento en Loja. Revista Cepal, (117), 69-86. Recuperado de: https://repositorio.cepal.org/bitstream/handle/11362/39465/1/REV117_AlarconOrdonez.pdf (01/07/2020).

Camacho, G., y Hernández, K. (2005). Cambio mi vida: migración femenina, percepciones e impactos. CEPLAES - Centro de Planificacion de Estudios 
Sociales,

(1),

1-127.

Recuperado

de:

http://americalatinagenera.org/newsite/images/doc_62_Migracion-femeninapercepciones-e-impactos.pdf (01/07/2020).

Carranza, Y. G., Jiménez, M., y Escamilla, S. (2018). Emprendimientos femeninos en Ecuador. Revista Publicando, 5 (14), 57-66. Recuperado de: https://revistapublicando.org/revista/index.php/crv/article/download/1094/pdf_8 $16(01 / 07 / 2020)$.

Coronel, N. J. (2011). Estudio del impacto de la migracion en los nucleos familiares en el Parroquia Santa Isabel durante el período septiembre 2010 a julio del 2011. Tesis de Pregrado. Facultad de Jurisporudencia y Ciencias Sociales y Políticas de la Universidad de Cuenca - Ecuador, 1-27. Recuperado de: http://dspace.ucuenca.edu.ec/handle/123456789/933 (01/07/2020).

ESPOL (2015). Reporte de competitividad global. Recuperado de http://www.espae.espol.edu.ec/images/documentos/publicaciones/libros/gemecu ador2014.pdf (01/07/2020).

Ferreres, J. B., y Querol, V. A. (2019). La multifuncionalidad del espacio rural: la potencialidad de los recursos vinícolas para el desarrollo local en el interior norte valenciano. TERRA. Revista de Desarrollo Local, (5), 126-147. DOI 10.7203/terra.5.14818

García, V. G., Sánchez, R. A., Martínez, V. R., y Pérez, C. R. (2016). Estudio sobre los emprendimientos de la economía simple en el Ecuador. Ciencias Holguín, 22 (1), $1-17$. Recuperado de: http://www.ciencias.holguin.cu/index.php/cienciasholguin/article/view/883/1028 (01/07/2020).

Huízar, M. A., Villanueva, R., y Rosales, G. (2016). Turismo y empleo de calidad, ¿una relación posible?. En S. M. Arnaiz, y C. Gauna (eds.), Los retos del turismo (pp. 167-183), Universidad de Guadalajara. Recuperado de: https://www.researchgate.net/publication/305399956_Turismo_y_empleo_de_ca lidad_Una_relacion_posible (01/07/2020).

Ibáñez, R., y Rodríguez, I. (2012). Tipología y antecedentes de la actividad turística: turismo tradicional y turismo alternativo. En A. Ivanova, y R. Ibáñez (eds.), Medio ambiente y política turística en México. Tomo I. Ecología, biodiversidad y desarrollo turístico (pp. 17-33), Secretaria de Medio Ambiente y recursos naturales, Universidad Autónoma de Baja California.

INEC. (2010). V Censo de Población y VI de Vivineda - Ecuador. Quito: Instituto de Estadísticas y Censos del Ecuador.

López, L. Ma . (2012). El cuidado de las hijas y los hijos durante la migración internacional de los padres y las madres. Ánfora, 19 (32), 117-136. Recuperado de: https://www.redalyc.org/pdf/3578/357834265006.pdf (01/07/2020).

Martínez, P. J. (2011). Migración internacional en América Latina y el Caribe. Comisión Económica para Amércia Latina y el Caribe (CEPAL).

Martínez-Quintana, V. (2017). El turismo de naturaleza. Un producto turistico sostenible. Arbor, 193 (785), a396. doi: http://dx.doi.org/10.3989/arbor.2017.785n3002.

Martínez-Quintana, V. (2019). Perspectiva sociológica turística en las sociedades del ocio. Madrid: Sanz y Torres. 
Martínez-Quintana, V., Sanagustín, M. V., y Blanco, R. (2018). Paisajes culturales como imágenes de destino: percepción y valoración como producto turístico. Pasos: Revista de Turismo y Patrimonio Cultural, 16 (4), 873-887. doi: https://doi.org/10.25145/j.pasos.2018.16.062.

Martínez-Quintana, V., y Martínez-Gayo, G. (2019). Empoderamiento y desigualdad en el trabajo turístico femenino. Una perspectiva comparada. Papers de Turisme, (62), 46-66. Recuperado de: https://dialnet.unirioja.es/servlet/articulo?codigo $=6958378 \&$ orden $=0 \&$ info $=$ link (01/07/2020).

Millán, Mª . G., Castro, Ma . S., y Morales, E. (2015). Análisis del empleo femenino en el sector turistico. Un estudio de caso en zona rural. En Vázquez, I. (coord.), Investigación y género, inseparables en el presente y en el futuro: IV Congreso Universitario Nacional Investigación y Género (pp. 1.169-1.182), Universidad de Sevilla. Recuperado de: https://idus.us.es/bitstream/handle/11441/40159/Pages\%20from\%20Investigacio n_Genero_12-1097-1508-6.pdf?sequence=1\&isAllowed=y (01/07/2020).

Montoya, R. C. (2015). Análisis de la participación de la mujer como guía de turismo de aventura en el Ecuador. Tesis de Grado y Posgrado. Universidad Católica del Ecuador. Recuperado de: http://repositorio.puce.edu.ec/handle/22000/8770 (01/07/2020).

Moreno, A. D., y Cañada, M. E. (2018). Dimensiones de género del trabajo turístico. Alba Sud Editorial. Recuperado de: http://www.albasud.org/publ/docs/81.pdf (01/07/2020).

Moreno, E. J. (2006). Feminización del fenómeno migratorio Ecuatoriano. Historia Actual Online, (11), 121-132. Recuperado de: https://dialnet.unirioja.es/descarga/articulo/2479534.pdf (01/07/2020).

Oyarvide, H. P., Nazareno, I., Roldán, A., y Ferrales, Y. (2016). Emprendimiento como factor del desarrollo turístico rural. Retos de la Dirección, 10 (1), 71-93. Recuperado de: http://scielo.sld.cu/pdf/rdir/v10n1/rdir06116.pdf (01/07/2020).

Pastor, R. V., y Martinez, R. (2011). El nuevo constitucionalismo latinoamericano. Fundamentos para una construcción doctrinal. Revista general de derecho público comparado, (9), 1-24.

Pazmiño, M. E., y Guayasamín, A. d. (2017). Proyecto de Investigación. Recuperado de https://even3storage.blob.core.windows.net/anais/59880.pdf

Rodríguez, D. L., García, B. R., y Lalangui, J. (2013). El aprovechamiento del recurso turístico de Zaruma desde la acción Universitaria. Revista de Investigación en turismo y desarrollo local TURyDES, 6 (14), 1-12. Recuperado de: https://azslide.com/el-aprovechamiento-del-producto-turistico-de-zaruma-desdela-accion-universitari_5a560e2a1723ddc23d4d7baa.html (01/07/2020).

Sandoval, A. D., Ordóñez, O., y Noblecilla, M. (2018). Percepción del perfil del turista para el aprovechamiento de los atractivos turísticos: Caso Cantón Pasaje, El Oro (Ecuador). RIAT: Revista Interamericana de Ambiente y Turismo, 14 (1), 14-21. Recuperado de: https://dialnet.unirioja.es/servlet/articulo?codigo $=6517407 \&$ orden $=0 \&$ info $=$ link (01/07/2020). 
Serrano, A. L., y Villafuerte, P. E. (2017). Indicadores turísticos: oferta y demanda de la ciudad patrimonial de Cuenca - Ecuador. Revista Latino Americana de Turismologia / RELAT, 3 (1), 58-68. Recuperado de: https://periodicos.ufjf.br/index.php/rlaturismologia/article/download/10027/4601 (01/07/2020).

Subiñas, A. M. (2007). La Institucionalización del "Mainstreaming” de Género en las Entidades Sin Ánimo de Lucro (Esals). Un estudio de casos; rostros y voces. Aguascalientes: Edifmsa.

Valdiviezo, C. M. (2018). La Investigación. Metodologías desmitificadoras delfenómeno social. Editorial Académica Española.

Vega, C. (2016). El retorno más allá del mito del emprendedor. El retorno más allá del mito del emprendedor de mujeres y hombres a su regreso a Ecuador desde España. Papers, Revista de Sociología, 101 (4), 415-449. Recuperado de: http://dx.doi.org/10.5565/rev/papers.2182

Villafuerte, H. I., Barrezueta, Q. A., y Corral, S. C. (2015). Desarrollo turístico de la ruta del oro y su área de influencia en los cantones Zaruma y Portovelo. Facultad de Ingeniería Marítima, Ciencias Biológicas, Océnicas y Recursos Naturales, ESPOL. Tesis de Grado. Recuperado de: http://www.dspace.espol.edu.ec/xmlui/handle/123456789/4623 (01/07/2020). 


\section{EXTENDED ABSTRACT ${ }^{4}$}

The entrepreneurship and employability in the tourism sector of returned immigrant women is studied here to learn about the difficulties of labour integration upon returning to their country of origin. This objective leads to investigate the opportunities for progress that they usually find in the tourism sector, and more specifically, in the 14 cantons of the Province of El Oro in Ecuador. The tourist development reached especially in the most virgin and under-exploited territorial areas is carried out, and two Focus Groups that show the obstacles and difficulties in the development of labour reintegration.

In effect, Ecuadorian returned immigrant women have undergone significant changes in abandonment in the customs of a society of origin, Ecuador, being forced to modify their cultural patterns of home care, upbringing and basic education of children to undertake work activities of strenuous effort and foreign to their country of origin. With the migratory exodus, they left an intermittent gap in their families to focus fully on economic tasks that would bring significant benefits, thus paying the cost of the absence caused to their families in the place of origin.

The return process coincides with a level of economic development at different speeds in the host countries where they come from, especially in Spain. They are returned women who now have a training level, a work experience and purchasing power that enables them to face a job reintegration, and a return to the family vacuum that they left at the time of their departure or, where appropriate, the start of a new one. lifetime. From here, the incorporation into society occurs through the incorporation into the labour market that entails difficulties according to the economic sectors mainly, insertion that will be led by entrepreneurship and employability in the tourism sector.

In the tourist area, entrepreneurship constitutes an alternative for the return to work of returned women. Likewise Harold (2015) expresses that entrepreneurial ideas are processes that relate the entrepreneurial individual with the institutions and the State, and this leads to turning entrepreneurship into a very complex social and economic phenomenon. Starting a business offers greater opportunities to enter the State and the person, although the perception of self-efficacy is lower in women than in men, and it is a factor that will partially determine the decision to undertake.

In the tourism entrepreneurship of returned women, it is positively influenced that tourism is one of the main economic activities in both developed and developing countries, but asymmetries between men and women have increased historical inequality. The social juxtapositions of women vis-à-vis men must be improved so that strategic practices and interests are incorporated as a transformative potential to modify gender relations and subordination structures.

The first objective is to discover the perspectives offered by the tourism sector with a starting hypothesis that affirms that tourism offers ample opportunities for job advancement to returned women. The quantitative methodology uses the documentary and descriptive analysis of the under-exploited natural tourist resources, the cultural landscapes as destination images, and the number of visitors that frequent the cantons of the Province of El Oro in 2017 and 2018 respectively.

\footnotetext{
${ }^{4}$ Traducción exclusiva de los autores / Authors' exclusive translation.
} 
The second objective aims to investigate the integration of returned women with training potential, consolidated work experience, and purchasing power achieved in the most difficult tourist sectors, and the vital trajectories they have had to go through. The methodology used has been qualitative through two Focus Groups for women returned from Spain and other countries.

Tourism with its dynamism and capacity for progress has become one of the potential axes for development in Ecuador, and although there are no figures on the productive ventures of returned migrant women (according to the global competitiveness report (ESPOL, 2015)), sustainable tourism is targeted as a still unexploited area in the natural resources of the Province of El Oro. The socioeconomic and local development context of the tourism sector is characterized by the polarization of traditional tourism and alternative tourism, where returned women are overrepresented in the first and underrepresented in the second.

There is enormous potential in the rural area of the Province of El Oro for the entrepreneurship of returned women, who can especially participate in local development with nature tourism. The places with the best possibilities for entrepreneurship and employability in the tourism sector are diverse, and most of them are located in the rural context. The city by its nature has become an area of high auditory, visual, and environmental contamination that affects the entire urban environment, which makes the resident look for new alternatives of oxygenation and recreation in the face of stressful modern life, and look for in rural and coastal areas contact with nature, which is the main patrimonial value of the Province of El Oro, since "nature tourism represents an enormous opportunity to contact the natural and healthy roots that people need in the habitats in which they live, and can act as compensation for the "comfort" of the polluted urban habitat and its stressful pace of life" (Martínez-Quintana, 2017:2).

From the two Focus Groups it is obtained that in the first one there is greater employability, while in the second one entrepreneurship predominates. Returned women are receptionists, hotel waitresses, restaurant employees and owners of restaurants in ports such as Jelí and Hualtaco, which correspond mainly to traditional tourism, although it must be taken into account, according to Moreno and Cañada (2018:14) "the tremendous responsibility that the tourism sector has if it intends to promote quality and decency in the employment it generates". Integration into the world of work through entrepreneurship in the tourism sector has been very favourable and with prospects for the future, and it is a fact that is confirmed in the two groups of returned women. The Province of El Oro as a border area has an intense mobility of people both in its coastal and inland areas with a remarkable natural heritage and biodiversity.

The comparative advantages with respect to other sectors that have driven them to join the labour market for tourism development are based on training, work experience and the purchasing power achieved, and are elements that are reinforced with innate qualities and those developed as personal charm, the ability to have personal relationships, possess other added values, punctuality, knowledge of other countries, and empathy with the tourists who arrive.

The most difficult tourist sectors are found in alternative tourism, and more specifically, in adventure tourism, as is the case of the activities carried out by tourist guides in which men prevail, since they are areas that require more effort physical as required by employers.

The greatest satisfaction they achieve in their life trajectories is obtained precisely from having obtained opportunities for personal, cultural growth and economic fulfilment, and 
having made profitable the previous experiences obtained in their life trajectory as migrants.

Finally, the life trajectories achieved include the discrimination experienced by age, educational level, sex, ethnicity, inequality in job opportunities for insertion into work, and its impact on the development of entrepreneurship and employability in the tourism sector, and it is a reality that hinders their work progress. Gender stereotypes, identities and traditional roles emerge in the collective imagination, both in women and in men. Consequently, the existence of the empowerment of returned women and inequality in the tourism sector are detected, when, according to Martínez-Quintana and Martínez-Gayo (2019), there is an exponential growth in tourism, in which women are in an anchored process of discontinuous progress and setbacks with permanent overrepresentation and underrepresentation in the job categories, without having yet reached a necessary adjustment between empowerment and equality. 


\section{CONTRIBUCIÓN SEGÚN AUTORES}

\begin{tabular}{|c|l|c|c|}
\hline \multicolumn{1}{|c|}{ ITEM } & $\begin{array}{c}\text { Violante Martínez } \\
\text { Quintana }\end{array}$ & $\begin{array}{c}\text { Miguel Ángel Ramón } \\
\text { Pineda }\end{array}$ \\
\hline 1 & Conceptualización & $50 \%$ & $50 \%$ \\
\hline 2 & Tratamiento de los datos & $50 \%$ & $50 \%$ \\
\hline 3 & Análisis formal & $50 \%$ & $50 \%$ \\
\hline 4 & Acceso financiación & $30 \%$ & $70 \%$ \\
\hline 5 & Investigación & $50 \%$ & $50 \%$ \\
\hline 6 & Metodología & $60 \%$ & $40 \%$ \\
\hline 7 & Gestión del proyecto & $70 \%$ & $30 \%$ \\
\hline 8 & Recursos & $50 \%$ & $50 \%$ \\
\hline 9 & Software & $0 \%$ & $0 \%$ \\
\hline 10 & Supervisión & $70 \%$ & $30 \%$ \\
\hline 11 & Validación & $70 \%$ & $30 \%$ \\
\hline 12 & Visualización & $70 \%$ & $30 \%$ \\
\hline 13 & Redacción (borrador) & $60 \%$ & $40 \%$ \\
\hline 14 & Redacción final (revisión y edición) & $70 \%$ & $30 \%$ \\
\hline
\end{tabular}

Para más información, visitar CRediT: https://casrai.org/credit/ 